\title{
MUJER Y CAMBIO SOCIAL EN LA EDAD MODERNA
}

María Antonia del Bravo

Madrid, Encuentro, 2009, 311 p.

La tesis en torno a la cual gira el libro de María Antonia del Bravo, es que la mujer ha sido el motor de los cambios sociales desde la Edad Moderna hasta nuestros días.

Delimitada por la autora, entre los siglos XV al XIX, la Modernidad transcurre entre el Renacimiento, el Barroco y la Ilustración. A lo largo de estas principales etapas, la cultura de la Modernidad se perfila con tres notas definitorias, que para Del Bravo son:

1. Un acento especial en lo relativo a las libertades individuales. Es decir, subrayar el hecho de que, en las distintas circunstancias de su vida, el hombre pueda actuar como desee.

2. Un énfasis en el individualismo. Que el hombre pueda realizar en cada momento lo que quiera, con plena independencia de quienes le rodean. Para ello ha de procurar no ligarse a nada ni a nadie de forma estable, pues toda ligazón, todo compromiso, puede restringir el ejercicio futuro de su libertad.

3. Una fe ciega en el progreso y un desprecio total por la tradición. Esta idea condujo a un optimismo descontrolado, que en cierto modo aún perdura, y dio lugar a una sobrevaloración de la cultura como fuente de todo bienestar y, al mismo tiempo, a la incuestionabilidad de los propios presupuestos ilustrados. 
Así, a partir de estos supuestos, la tesis del libro se desarrolla a lo largo de cuatro capítulos en los que se analizan tres temas.

El primero, asienta la importancia de la mujer en la sociedad Moderna, en la que familia y religión juegan un papel fundamental. Aquí se plantea que el matrimonio cristiano fue una institución cardinal para mejorar la situación de la mujer en la familia y en la sociedad. Quizá por esta razón, entre otras, muchas mujeres contribuyeron directamente al desarrollo de la civilización cristiana europea. Desde un primer momento, en la época romana, muchas veces fueron ellas las primeras que se convirtieron al catolicismo y luego evangelizaron a sus familias. Posteriormente, el derecho canónico, aunque reconocía la autoridad del marido sobre la mujer, insistía también en la necesidad de que hubiera libre consentimiento por ambas partes para construir un matrimonio válido, lo cual representó un progreso femenino fundamental.

Previamente al Concilio de Trento, y mucho más después de su celebración, se produjo una importante literatura legislativa, doctrinal y moral: instrucciones, diálogos, cartas, tratados y manuales de confesores y predicadores, entre otras, preocupada por educar a cada miembro de la familia conforme a los patrones preestablecidos desde la corrección a la hora de elegir estado hasta la autoridad indiscutible de la patria potestad, pasando por reglamentar la conducta de los esposos, la educación de los hijos y las relaciones paterno-filiales. Cabe decir, también, que los mencionados tratados tuvieron en cuenta, en palabras de la autora, la verdadera esencia del amor, no como punto de salida, sino más bien de llega$\mathrm{da}, \mathrm{y}$, partiendo de ella, propusieron el modo de conseguir la estabilidad social. A saber: tener hijos y educarlos correctamente, cimentar la fidelidad y la indisolubilidad matrimoniales.

Se creía posible alcanzar la estabilidad deseada en la familia y, por extensión, la buena marcha de la sociedad, mediante estos bienes del matrimonio, aunque como es sabido, no fue así en muchos casos. Y precisamente la falta contra dichos bienes fueron considerados por tratadistas de la época (Antonio de Nebrija, Pedro de Luxan, Francisco Manuel de Mello, Luis Vives, entre otros), como una de las principales causas de desmoronamiento moral y declinación social. 
El segundo tema del libro es el relativo a la mujer y el cambio social. Aquí, la autora destaca a aquellas mujeres españolas —nacidas o no en la metrópoli- que traspasaron las fronteras de lo privado (a que la sociedad las tenía confinadas), pero sin aceptar ese principio básico de la Modernidad que suponía disociar la ética del trabajo, la política o la cultura. Por ejemplo: Isabel la Católica y Catalina de Aragón, en el campo de la política; Florencia Pinar y Sor Juana Inés de la Cruz, en el campo de la cultura, entre otras. Estas mujeres, no obstante la progresiva radicalización y subjetivación de la libertad humana que se presentó a lo largo de la Modernidad, fueron protagonistas del cambio social y garante de los valores en el ámbito familiar, toda vez que fueron capaces de incorporarse a la vida activa de forma creativa. En decir de la autora:

(...) con una antropología más tendente a la conjunción que a la disyunción, con una clara orientación hacia las relaciones interpersonales y hacia la empatía, estas mujeres hicieron las cosas bien, realizaron cambios necesarios, sin perder su propia identidad.

En el tercer y último tema del texto, la autora afirma que históricamente tanto los hombres como las mujeres han desarrollado de forma reduccionista sus capacidades y han llevado a cabo una parcial comprensión del mundo, porque no han desplegado plena ni adecuadamente su ser personal. Es decir, se trata de desbloquear una reducida concepción de lo específico y de lo no-específico de los hombres y de las mujeres. En este sentido, la puesta en marcha de una sociedad activa obliga a reconsiderar el papel de las mujeres en la economía, lo que implica redefinir las relaciones entre los factores socioeconómicos y políticos que, hoy por hoy, les impiden participar plenamente en la actividad y limitan sus opciones de vida. Conciliar vida familiar y actividad profesional y hacer posible que hombres y mujeres compartan las mismas funciones son objetivos inherentes al cambio requerido en este nuevo siglo.

Asimismo como otrora los tratadistas de la Modernidad estimaron que una sociedad no podía ser mejor que las familias que la componían, la sociedad del siglo XXI ha de vincular nuevamente como una unidad, a la familia y a la sociedad activa, lo que plantea por un lado, el reto de ir contra lo que Del Bravo denomina «ideología de la desvinculación»—que 
eleva a rango de modelo deseable, disfunciones que atañen a la familia y que traen gravísimas consecuencias personales y sociales- $y$, por otro lado, el gran reto de nuestro tiempo es la interdependencia a la que hay que llegar superando las nociones falsas de dependencia (femenina) e independencia (masculina). Se trata en síntesis, de vivir los unos con los otros.

Mónica del Carmen Meza Mejía 